\title{
Determinants of the use of physiotherapy services among individuals with Parkinson's disease living in Brazil
}

\author{
Determinantes do uso de serviço de fisioterapia entre indivíduos com doença de \\ Parkinson que vivem no Brasil \\ Fátima Rodrigues-de-Paula1, Raquel de Carvalho Lana', Larissa Karlla Rodrigues Lopes ${ }^{1}$, Francisco \\ Cardoso ${ }^{2}$, Ana Raquel Rodrigues Lindquist ${ }^{3}$, Maria Elisa Pimentel Piemonte ${ }^{4}$, Clynton Lourenço Correa ${ }^{5}$, \\ Vera Lúcia Israel6, Felipe Mendes ${ }^{7}$, Lidiane Oliveira Lima ${ }^{8}$
}

\begin{abstract}
To identify the factors affecting the use of physiotherapy services among individuals with Parkinson's disease (PD) living in Brazil. Methods: Overall, 479 individuals with idiopathic PD, of both sexes, at any stage of the Hoehn \& Yahr (HY) scale, and from seven capital cities in Brazil were recruited from 2014 to 2016. Multivariate logistic regression was the main statistical tool. For the construction of the logistic model, the association of the dependent variable "physiotherapy" with the independent sociodemographic/economic and clinical variables: age, education, family income, time of PD since onset, HY, the activities of daily living and motor subscales of the Unified Parkinson's Disease Rating Scale, cognitive aspects, depressive symptoms, fear of falling, freezing gait, history of falls, physical activity level, gait speed, walking performance and balance, were verified. Results: The 479 individuals had an average age of $65.2 \pm 11.0$ years, $88 \%$ were in the HY I-III stages and $43.4 \%$ were under physiotherapy treatment. The analysis identified two determinant variables related to the use of the physiotherapy service: level of education $(\mathrm{OR}=1.24)$ and walking performance $(\mathrm{OR}=0.82)$. Decreased walking performance and a higher educational level increased the use of a physiotherapy service in individuals with PD living in Brazil. Conclusions: The present study shows that individuals with PD, residents from different regions of Brazil, have limited access to physiotherapy services. In addition, the Brazilian Public Health Care System, as well as local programs, need to target PD individuals with a low educational level to improve their access to physiotherapy services. Goals should aim towards the development of physical exercise programs to improve the patients' functional performance for a longer period.
\end{abstract}

Keywords: Parkinson disease; physical therapy specialty; education; gait.

\section{RESUMO}

Descrever a utilização do serviço de fisioterapia e identificar os fatores que determinam o uso desse serviço entre indivíduos com doença de Parkinson (DP) que vivem no Brasil. Métodos: No total, 479 indivíduos com DP idiopática, de ambos os sexos, em qualquer estágio da escala de Hoehn \& Yahr (HY) e de sete capitais do Brasil foram recrutados durante 2014 a 2016. A análise de regressão logística multivariada foi a principal ferramenta de análise estatística. Para a construção do modelo logístico foi investigada a associação da variável dependente "fisioterapia" com variáveis independentes sociodemográficas, econômicas e clínicas: idade, educação, renda familiar, tempo de DP desde o início, HY, domínio motor e atividade de vida diária da Unified Parkinson's Disease Rating Scale, aspectos cognitivos, sintomas depressivos, medo de queda, congelamento marcha, história de quedas, nível de atividade física, velocidade de marcha, capacidade de caminhar e equilíbrio. Resultados: 479 indivíduos apresentaram média de 65,2 $\pm 11,0$ anos, 88\% tiveram HY = I-III e 43,4\% faziam fisioterapia para a DP. A análise identificou duas principais variáveis determinantes do uso da fisioterapia: educação $(O R=1,24)$ e capacidade de caminhada $(\mathrm{OR}=0,82)$. A diminuição da capacidade de caminhar e maior nível educacional aumentam o uso da fisioterapia em indivíduos com doença de Parkinson vivendo no Brasil. Conclusões: 0 presente estudo mostra que indivíduos com DP, residentes de diferentes regiões do Brasil, têm acesso limitado aos serviços de fisioterapia. Além disso, o Sistema Brasileiro de Saúde Pública, bem como os programas locais, precisam atingir pessoas de DP com baixo nível educacional para melhorar seu acesso aos serviços de fisioterapia. Os objetivos devem ser para o desenvolvimento de programas de exercícios físicos para melhorar o desempenho funcional dos pacientes por um período mais longo.

Palavras-chave: doença de Parkinson; fisioterapia; educação; marcha.

\footnotetext{
${ }^{1}$ Universidade Federal de Minas Gerais, Departamento de Fisioterapia, Belo Horizonte MG, Brasil;

${ }^{2} U$ niversidade Federal de Minas Gerais, Departamento de Clínica Médica, Belo Horizonte MG, Brasil;

${ }^{3}$ Universidade Federal do Rio Grande do Norte, Departamento de Fisioterapia, Natal RN, Brasil;

«Universidade de São Paulo, Departamento de Fisioterapia, São Paulo SP, Brasil;

${ }^{5}$ Universidade Federal do Rio de Janeiro, Departamento de Fisioterapia, Rio de Janeiro RJ, Brasil;

${ }^{6}$ Universidade Federal do Paraná, Universidade de Fisioterapia, Curitiba PR, Brasil;

7Universidade de Brasília, Departamento de Fisioterapia, Brasília DF, Brasil;

${ }^{8}$ Universidade Federal do Ceará, Departamento de Fisioterapia, Fortaleza CE, Brasil.
}

Correspondence: Fátima Rodrigues-de-Paula; Departamento de Fisioterapia / UFMG; Av. Antonio Carlos, 6627; $31270-901$ Belo Horizonte MG, Brasil; E-mail: fatimarp@globo.com

Conflict of interest: There is no conflict of interest to declare.

Support: CNPq

Received 27 September 2017; Received in final form 18 May 2018; Accepted 05 June 2018. 
Parkinson's disease (PD) is a multisystem neurodegenerative disease whose prevalence increases with aging, as well as differing significantly among geographical regions ${ }^{1}$. Higher rates are observed in South America compared with Europe and North America, regardless of the age group $^{1}$. In Brazil, a prevalence rate of 3,300 per 100,000 individuals over the age of 64 years has been estimated, one of the highest in relation to other countries ${ }^{2}$. Considering the aging of the population in Latin America, it is expected that the number of people with PD in Brazil will increase proportionally ${ }^{3,4}$.

Parkinson's disease is characterized clinically by an insidious onset and slowly-progressive course. The first symptoms appear with reduction of $80 \%$ of the dopamine produced by the cells in the substantia nigra ${ }^{5}$. The results are motor signs characterized by rigidity, bradykinesia and tremor, in addition to nonmotor symptoms like anosmia, constipation and REM sleep behavior disorders ${ }^{6}$. The natural progression of the disease and the gradual decrease in the efficacy of drugs result in loss of mobility and independence, with important gait deficits ${ }^{7}$ and restrictions in social life ${ }^{8}$.

Physiotherapy is an important resource to improve the functional status of patients with $\mathrm{PD}^{9}$. Additionally, specialized physiotherapy is associated with fewer PD-related complications and lower costs in daily clinical practice ${ }^{10}$. However, patients with PD have to deal with the deficiency of certain allied health services in the community ${ }^{11}$. A survey on PD in the United States reported that only $18.4 \%$ of patients had seen a physiotherapist ${ }^{12}$. Data on the rate of patients with PD living in Brazil who had access to physiotherapy, and which factors are related to its use, are unavailable.

Fear of falling, low expectations and lack of time to perform physical activity appear to be important perceived barriers to physical activity in individuals with $\mathrm{PD}^{13}$. In Brazil, all these aspects, associated with the PD patients' lower level of education and health condition ${ }^{14}$, may exacerbate their barriers to using physiotherapy services ${ }^{4}$. Based on this information, we conducted a study to identify the use of physiotherapy services and determine which factors (social, economic and clinical) affect the use of physiotherapy services among individuals with PD living in Brazil.

\section{METHODS}

The REPARK-BR is a cross-sectional multicentric study based on questionnaires and clinical evaluations conducted between the years of 2014 and 2016. The research net is organized in six zones, distributed over seven state capitals of Brazil, including: Belo Horizonte (Minas Gerais), São Paulo (São Paulo), Rio de Janeiro (Rio de Janeiro), Curitiba (Paraná), Natal (Rio Grande do Norte), Fortaleza (Ceará) and Brasília (Distrito Federal). In each zone, a public university was responsible for the study, but the main coordinator group was located at the Universidade Federal de Minas Gerais, Belo Horizonte, Minas Gerais, Brazil.

\section{Participants}

Individuals with PD were recruited consecutively from the community, health centers, and public and private clinics of the institutions involved in the study. Participants in the study comprised 479 males and females with idiopathic PD diagnosed by neurologists specialized in movement disorders, according to the UK Brain Bank Criteria ${ }^{15}$. The participants were in any stage of the Hoehn \& Yahr disability scale $(\mathrm{HY})^{16}$. Individuals with other types of parkinsonism or other neurologic diseases that could interfere in the performance of the tests were excluded.

Professors, graduate and undergraduate students of the universities involved collected the data. They all received training by the main group coordinator. Each collaborator received a manual with the instructions on how to collect the data. Data collection lasted, on average, 240 minutes. After screening for the inclusion criteria, the potential participants received information about the objectives of the research, their voluntary participation and right to leave the study at any time, the confidentiality of the information collected and the absence of physical and mental health risks by participating in the study. After accepting the invitation, the participants signed the informed consent form that was approved by the ethics committee of the institutions involved (CAAE= 15050713.6.1001.5149).

\section{Data collection}

The dependent variable analyzed was the question: Are you treating PD with physiotherapy?

The data included two categories:

1) Sociodemographic and economic: age, sex, mass, height, state and city, marital status, educational level (years of study completed), family income, occupation and whether living alone or accompanied;

2) Clinical characteristics: duration of PD since onset, daily dosage of levodopa, related PD surgeries, HY disability scale, the Unified Parkinson's Disease Rating Scale (UPDRS), cognitive aspects, depressive symptoms, fear of falling, freezing gait, history of falls, physical activity level, gait speed, walking performance and balance.

For PD severity, we used the domains Activity of Daily Living (ADL) and Motor Examination of the $\mathrm{UPDRS}^{17}$, in addition to the HY, which included five stages of classification $^{16}$. Patients classified in stages I and II of the HY had mild disability, those in stage III had moderate disability, and patients classified in stages IV and V had severe disability ${ }^{18}$.

The cognitive assessment was obtained using the Montreal Cognitive Assessment, a quick, practical, and effective cognitive screening instrument that distinguishes the performance of adults with cognitive deficits due to aging and adults with cognitive impairment ${ }^{19}$. One point 
was added to the individuals who had 12 years of schooling or less. Individuals with a cutoff of 26 had mild cognitive impairment and those with a cutoff of 21 had dementia $^{20}$. Depression was assessed using the Brazilian version of the Geriatric Depression Scale ${ }^{21}$. This scale has a cutoff point equal to, or greater than $8 / 9$ to detect depressive symptoms ${ }^{22}$.

Fear of falling was measured with the Falls Efficacy Scale - International ${ }^{23,24}$. This scale has excellent internal consistency and test-retest reliability in $\mathrm{PD}^{23}$. The items are related to physical or social activities and the scores range from 16 (absence of concern) to 64 points (extreme concern) regarding the possibility of falling when performing a daily activity. The Freezing of Gait Questionnaire was used to evaluate the individuals' subjective perception of severity and the impact of freezing of gait performance. The higher the score, the more affected was the gait by freezing ${ }^{25}$.

The history of falls was measured by the number of falls that had occurred in the previous year. As recommended by the Kellogg International Work Group on the Prevention of Falls in the Elderly ${ }^{26}$, an operational fall definition was provided for each participant: "Unexpected loss of balance in which you hit the floor, surface or object such as a chair, bench, sofa, toilet, below the knee level”. Participants who reported no or one fall in the 12 months prior were classified as non-fallers, and with two or more falls as recurrent fallers ${ }^{26}$

The level of physical activity of the individuals in this study was assessed through the Human Activity Profile. Individuals were classified according to predefined cutoff points as inactive (less than 53), moderately active (between 53 and 74) or active (greater than 74$)^{27}$. Gait velocity was measured with the 10-meter walking test, a simple and reliable measure for individuals with $\mathrm{PD}^{28}$. The participants were asked to walk at their self-selected speed for a 14-meter distance and the time taken to traverse the 10 central meters was timed. The average of three measurements was used for the analysis. Walking performance was measured with the six-minute walk test, which is widely used within clinical settings to assess functional capacity, including in PD patients. The distance covered in meters in six minutes was recorded and used for analysis ${ }^{29}$.

Balance performance was measured through the MiniBESTest that comprises 14 items divided into four areas: 1) anticipatory postural adjustments; 2 ) reactive postural control; 3) sensory orientation and 4) dynamic gait. The Brazilian version of the Mini-BESTest has shown good reliability, construct validity, response stability and capability of discriminating different balance levels in individuals with $\mathrm{PD}^{30}$.

\section{Data analysis}

Data was saved in an electronic database, supervised and confirmed by two trained evaluators to guarantee $100 \%$ agreement. Subsequently, two supervisors and one statistician checked the data from all zones. Descriptive statistics, tests for normality (Kolmogorov-Smirnov), and equality of variances (Levene's test) were applied for all outcomes. Descriptive analyses, measures of central tendency and dispersion (mean, standard deviation) were used for quantitative variables, and frequency for categorical variables. For the construction of the logistic model, the associations of the dependent variable "physiotherapy" ( $0=$ no and $1=$ yes) with the following independent variables were verified: age, gender, education, family income, duration of PD since onset, HY, the Activity of Daily Living and Motor subscales of the UPDRS, cognitive aspects, depressive symptoms, fear of falling, freezing gait, history of falls, physical activity level, gait velocity, walking performance and balance. The choice of independent variables for possible inclusion in the model was based on a theoretical foundation.

A multiple logistic regression analysis was conducted to predict the use of a physiotherapy service. The forward stepwise method was applied to determine the best fit model in which all variables were significant $(p<0.05)$. The forward stepwise method begins with a model with no explanatory variables. At each step, a variable is added to the model to determine the best fit model with all significant variables. The method stops when the addition of any other explanatory variable to the model results in one or more variables being not significant. The strength of the relationship between the independent variable and each dependent variable was measured by the odds ratio (OR) with a confidence interval of $95 \%$ (95\%CI).

\section{RESULTS}

A total of 479 individuals with PD participated in the study. The distribution of the participants by city (percentage and absolute number) is presented in the Figure. The participants had an average age of $65.2 \pm 11.0$ years, with mean weight of $70.1 \pm 13.9 \mathrm{Kg}$ and mean height of $1.64 \pm 0.10$ meters. During evaluation, $43.5 \%$ of the participants were in physiotherapy treatment and $75.2 \%$ did not participate in any other therapeutic activity. Among the therapeutic activities performed by the participants, $18.3 \%$ were in speech therapy, $7.5 \%$ in occupational therapy and $5.6 \%$ in psychology treatment.

The sociodemographic and economic characteristics of the participants are described in Table 1. The clinical characteristics of participants included in this study are presented in Table 2. In relation to the cognitive level, $48 \%$ presented with dementia and $34.9 \%$ presented with a mild cognitive disability. Depressive symptoms were present in $25 \%$ of the participants. The average number of falls in the previous year was $5.7 \pm 26.9$ and $42.9 \%$ were classified as fallers. Of the participants, $39 \%$ were classified as inactive, $39 \%$ as moderately active and $22 \%$ as active.

The dependent variables selected according to the methodology described above were education and walking 


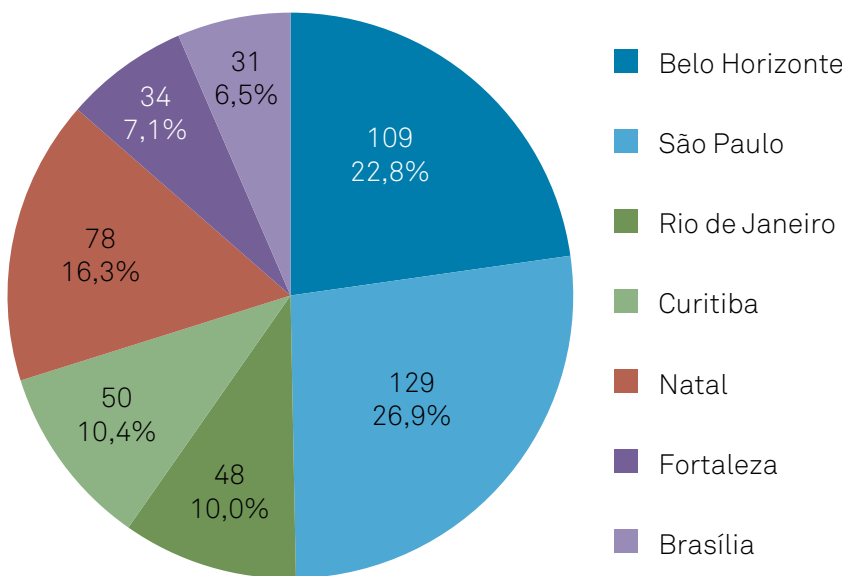

Figure. Distribution of the participants (absolute number and percentage) by city $(n=479)$.

Table 1. Sociodemographic and economic characteristics of the participants with PD $(n=479)$.

\begin{tabular}{|c|c|c|}
\hline Variable & $n$ & $\%$ \\
\hline \multicolumn{3}{|l|}{ Sex } \\
\hline Men & 301 & 63 \\
\hline Women & 178 & 37 \\
\hline \multicolumn{3}{|l|}{ Origin } \\
\hline Public clinic & 192 & 40 \\
\hline Private clinic & 34 & 7 \\
\hline Hospital & 20 & 4 \\
\hline Community & 43 & 4 \\
\hline Associations & 190 & 40 \\
\hline \multicolumn{3}{|l|}{ Marital status } \\
\hline Single & 41 & 9 \\
\hline Married & 333 & 70 \\
\hline Widowed & 61 & 13 \\
\hline Separated & 44 & 9 \\
\hline \multicolumn{3}{|l|}{ Education } \\
\hline No education & 18 & 4 \\
\hline Primary school & 203 & 42 \\
\hline High school & 129 & 27 \\
\hline Higher education & 98 & 20 \\
\hline Graduate program & 31 & 6 \\
\hline \multicolumn{3}{|l|}{ Family income* } \\
\hline$<1 \mathrm{MW}$ & 16 & 3 \\
\hline $1 \mathrm{MW}$ & 72 & 15 \\
\hline 1 to $4 \mathrm{MW}$ & 230 & 48 \\
\hline$>4$ to $8 \mathrm{MW}$ & 89 & 19 \\
\hline$>8$ to $12 \mathrm{MW}$ & 40 & 8 \\
\hline$>12 \mathrm{MW}$ & 30 & 6 \\
\hline Did not answer & 2 & 4 \\
\hline \multicolumn{3}{|l|}{ Occupation } \\
\hline Retired & 377 & 79 \\
\hline Active & 71 & 15 \\
\hline Unemployed & 9 & 2 \\
\hline License / pension & 5 & 1 \\
\hline Domestic life & 17 & 4 \\
\hline \multicolumn{3}{|l|}{ Lives } \\
\hline Alone & 38 & 8 \\
\hline Accompanied & 441 & 92 \\
\hline
\end{tabular}

MW: minimum wage; * The minimum wage at the time of data collection corresponded to $\mathrm{R} \$ 1005.95$ or approximately US $\$ 295$ dollars (today's value; quotation: $\mathrm{R} \$ 3.41$ on 16/Mar/2018). performance (distance covered in the six-minute walk test). Table 3 shows the detailed results of the logistic regression analysis, including the p-value and estimated OR with $95 \%$ CI. In order to simplify the interpretation of the results, each unit in the walking performance variable corresponded to 100 meters. A one-year increase in the educational level increased the probability of using a physiotherapy service by $24.7 \%$ (OR-1). For the variable walking performance, an increase of a distance of 100 meters reduced the probability of using a physiotherapy service by $17 \%$ (OR-1). A decrease of 100 meters increased the probability of using a physiotherapy service by $20 \%$ (OR-1).

\section{DISCUSSION}

This study provides primary data regarding the use of physiotherapy services among individuals with PD in Brazil. It may be the first study that has attempted to gain an insight into the factors (sociodemographic, economic and clinical) associated with the use of physiotherapy services. The main results of our study show that $43.5 \%$ of the participants had physiotherapy treatment prescribed because of their disease. In addition, the findings showed that educational level and walking performance (measured in years of study completed and distance covered in the six-minute walk test, respectively) remained in the final model after adjusting for the effects of all the other variables.

Almost $57 \%$ of the participants in the study had not had physiotherapy treatment and $75.2 \%$ did not do other therapeutic activities. These findings indicate the deficiency of the health care system towards patients with PD. It is alarming that a large part of this group had limited access to physiotherapy or any other therapy. Our results agree with results reported from other similar studies. The numbers vary considerably from country to country, ranging from $7 \%$ in the United Kingdom ${ }^{31}, 18.4 \%$ in the United States of America ${ }^{12}$ and $60 \%$ in the Netherlands ${ }^{32}$. Although Brazil showed a high

Table 2. Specific characteristics of the participants with PD $(n=479)$.

\begin{tabular}{lcc}
\hline Variable & Mean (SD) & Min-Max \\
\hline Time since diagnosis (years) & $7.1(5.5)$ & $0.08-49$ \\
Levodopa (mg) & $563(375)$ & $25-2.500$ \\
UPDRS III - Motor (0-108) & $26.6(16.1)$ & $0.0-76$ \\
UPDRS II - ADL (0-52) & $14.9(7.9)$ & $0.0-47$ \\
Hoehn \& Yahr (HY) (I-V) & $2.4(0.9)$ & $0-5$ \\
FOG-Q; (0-16) & $8.8(5.8)$ & $1-24$ \\
MoCA total; (0-30) & $20.1(5.5)$ & $3-30$ \\
GDS 15; (0-15) & $5.4(3.3)$ & $1-15$ \\
\hline
\end{tabular}

UPDRS: Unified Parkinson's Disease Rating Scale; ADL: Activities of Daily Living; SD: standard deviation; FOG-Q: Freezing Gait Questionnaire; MoCA: Montreal Cognitive Assessment; GDS: Geriatric Depression Scale. 
Table 3. Influence of sociodemographic, economic and clinical variables on physiotherapy service use.

\begin{tabular}{|c|c|c|c|c|c|}
\hline Variable & Estimate & $95 \% \mathrm{Cl}$ & $p$-value & OR & $95 \% \mathrm{Cl}$ \\
\hline Age & 0.01 & $-0.00-0.02$ & 0.19 & 1.01 & $0.99-1.02$ \\
\hline Gender & 0.28 & $-0.08-0.46$ & 0.13 & 1.33 & $0.92-1.59$ \\
\hline Family income & 0.10 & $-0.05-0.20$ & 0.19 & 1.11 & $0.95-1.23$ \\
\hline Duration of PD since onset & 0.00 & $-0.02-0.05$ & 0.56 & 1.01 & $0.98-1.06$ \\
\hline \multicolumn{6}{|l|}{ Daily dosage of levodopa } \\
\hline History of falls & 0.03 & $-0.35-0.69$ & 0.85 & 1.03 & $0.72-1.99$ \\
\hline UPDRS-ADL & -0.02 & $-0.04-0.06$ & 0.06 & 0.97 & $0.96-1.07$ \\
\hline UPDRS-Motor & -0.00 & $-0.01-0.02$ & 0.25 & 0.99 & $0.98-1.03$ \\
\hline HY & 0.05 & $-0.13-0.32$ & 0.60 & 1.05 & $0.87-1.38$ \\
\hline Cognitive aspects & 0.04 & $0.01-0.02$ & 0.08 & 1.04 & $1.01-1.02$ \\
\hline Depression & -0.04 & $-0.10-0.15$ & 0.06 & 0.95 & $0.90-1.16$ \\
\hline Fear of falling & 0.01 & $-0.00-0.02$ & 0.21 & 1.01 & $0.99-1.02$ \\
\hline Freezing of gait & 0.00 & $-0.03-0.05$ & 0.99 & 1.00 & $0.97-1.06$ \\
\hline Physical activity level & -0.00 & $-0.01-0.01$ & 0.68 & 0.99 & $0.99-1.02$ \\
\hline Gait velocity & -0.13 & $-0.72-1.28$ & 0.64 & 0.87 & $0.48-3.62$ \\
\hline Balance & 0.01 & $-0.01-0.03$ & 0.27 & 1.01 & $0.99-1.04$ \\
\hline Education & 0.22 & $0.01-0.43$ & 0.03 & 1.25 & $1.01-1.53$ \\
\hline Walking capacity* & -0.19 & $-0.37--0.01$ & 0.04 & 0.83 & $0.69-0.99$ \\
\hline
\end{tabular}

95\% Cl: $95 \%$ confidence interval; OR: odds ratio relative to the increase of one unit of the variable; UPDRS: Unified Parkinson's disease rating scale; ADL: Activities of daily living; HY: Hoehn \& Yahr.

*each 100 meters.

percentage of patients using the physiotherapy servicesexcept compared with the Netherlands-this result should be interpreted carefully. In Brazil, the healthcare system is public, and the participants in the study were from the public system, which might justify the $43 \%$ compared with the other countries. Although access to physiotherapy might be easier because of the public characteristic of the health system, there are social and clinical factors that are determinants for the use of these services.

Our research findings support the relationship between the level of education and the use of the health care system. They indicate that better-educated patients acquire more information about their rights to access the benefits of physiotherapy than less educated patients. The profile of the participants with PD from the different cities included a majority of elderly males, who were retired, with a low education level and low income, originally from public clinics and who had limited access to physiotherapy treatment. About $4 \%$ had no education, $42 \%$ had primary education and $27 \%$ had secondary education. Thus, the lower education level of the participants may have been a barrier to accessing and using physiotherapy treatment. Studies in developing countries have shown that a low education level may affect the degree of understanding of the prescribed treatment, as well as adherence to $^{33,34}$ and satisfaction with the treatment ${ }^{35}$. This result requires a scientific approach to understand the best strategies to maximize access of the low-educated PD patient to physiotherapy services. Educational booklets and the development of continuous health education strategies by multiprofessional teams, appropriate for people with lower education levels, have been shown to result in a better understanding of treatment procedures among patients ${ }^{36,37}$.

Walking performance (six-minute walk test) was significantly associated with the use of physiotherapy services in this study. The results suggest that the greater the distance covered, the lower the use of physiotherapy services. The six-minute walk test has also been used as a measure of functional status in patients with $\mathrm{PD}^{29}$, as well as a predictor of morbidity and mortality ${ }^{38}$. If the walking function of PD patients is preserved for a longer period of time, there would be less need to use physiotherapy services. It is known that endurance exercise programs are effective and improve functional performance ${ }^{39}$. Recently, a meta-analysis showed that walking and cycling for 20 minutes or more per session with a frequency of three or more per week and intensity from "moderate" to "vigorous", had a positive effect on the UPDRS ${ }^{39}$. Based on the benefits of physical activity and mobility in patients with PD, public policies should focus on strategies to maintain patients' function and mobility for a longer period of time.

The findings of this study have important implications for policy design and service delivery. The need to improve awareness among individuals with PD about the condition and services required to understand the utilization of 
physiotherapy is apparent. Efforts are needed to improve awareness and facilitate the use of physiotherapy services, especially in individuals with PD and a low educational level.

This study has positive aspects and some limitations. The benefits of multicenter data include a larger number of participants, different geographic locations and inclusion of patients at different stages, increasing the external validity of the study. One of the limitations of this study is its cross-sectional nature, preventing determination of a cause-and-effect relationship. In addition, this study lacks data from the north region of Brazil, which may be a limitation as well.
In conclusion, the present study shows that individuals with PD, residents from different regions of Brazil, have limited access to physiotherapy services. In addition, the Brazilian Public Health Care System, as well as local programs, need to target PD individuals with a low educational level to improve their access to physiotherapy services. Goals should include the development of physical exercise programs to improve the patients' functional performance for a longer period. The present data are important to guide resource application and training of personnel in the care of individuals with PD in Brazil.

\section{References}

1. Pringsheim T, Jette N, Frolkis A, Steeves TD. The prevalence of Parkinson's disease: a systematic review and meta-analysis. Mov Disord. 2014 Nov;29(13):1583-90. https://doi.org/10.1002/mds.25945

2. Barbosa MT, Caramelli P, Maia DP, Cunningham MC, Guerra HL, Lima-Costa MF et al. Parkinsonism and Parkinson's disease in the elderly: a community-based survey in Brazil (the Bambui study). Mov Disord. 2006 Jun;21(6):800-8. https://doi.org/10.1002/mds.20806

3. Bovolenta TM, Felício AC. Parkinson's patients in the Brazilian Public Health Policy context. Einstein (Sao Paulo). 2016 Jul-Sep;14(3):7-9. https://doi.org/10.1590/S1679-45082016ED3780

4. Sánchez JL, Buriticá O, Pineda D, Uribe CS, Palacio LG. Prevalence of Parkinson's disease and parkinsonism in a Colombian population using the capture-recapture method. Int J Neurosci. 2004 Feb;114(2):175-82. https://doi.org/10.1080/00207450490269444

5. Dauer W, Przedborski S. Parkinson's disease: mechanisms and models. Neuron. 2003 Sep;39(6):889-909. https://doi.org/10.1016/S0896-6273(03)00568-3

6. Martinez-Martin P. The importance of non-motor disturbances to quality of life in Parkinson's disease. J Neurol Sci. 2011 Nov;310(12):12-6. https://doi.org/10.1016/j.jns.2011.05.006

7. Jankovic J. Gait disorders. Neurol Clin. 2015 Feb;33(1):249-68. https://doi.org/10.1016/j.ncl.2014.09.007

8. Poewe W, Mahlknecht P. The clinical progression of Parkinson's disease. Parkinsonism Relat Disord. 2009 Dec;15(4 Suppl 4):S28-32. https://doi.org/10.1016/S1353-8020(09)70831-4

9. Tomlinson CL, Patel S, Meek C, Herd CP, Clarke CE, Stowe R et al. Physiotherapy versus placebo or no intervention in Parkinson's disease. Cochrane Database Syst Rev. 2013 Sep;9(9):CD002817. https://doi.org/10.1002/14651858.CD002817

10. Ypinga JH, Vries NM, Boonen LH, Koolma X, Munneke M, Zwinderman $\mathrm{AH}$ et al. Effectiveness and costs of specialised physiotherapy given via ParkinsonNet: a retrospective analysis of medical claims data. Lancet Neurol. 2018 Feb;17(2):153-61. https://doi.org/10.1016/S1474-4422(17)30406-4

11. Keus SH, Munneke M, Nijkrake MJ, Kwakkel G, Bloem BR. Physical therapy in Parkinson's disease: evolution and future challenges. Mov Disord. 2009 Jan;24(1):1-14. https://doi.org/10.1002/mds.22141

12. Fullard ME, Thibault DP, Hill A, FoxJ, Bhatti DE, Burack MA et al. Utilization of rehabilitation therapy services in Parkinson disease in the United States. Neurol. 2017 Sep;89(11):1162-9. https://doi.org/10.1212/WNL.0000000000004355

13. Ellis T, Boudreau JK, DeAngelis TR, Brown LE, Cavanaugh JT, Earhart GM et al. Barriers to exercise in people with Parkinson disease. Phys Ther. 2013 May;93(5):628-36. https://doi.org/10.2522/ptj.20120279
14. Szwarcwald CL, Souza-Júnior PRB, Damacena GN. Socioeconomic inequalities in the use of outpatient services in Brazil according to health care need: evidence from the World Health Survey. BMC Health Serv Res. 2010;10:217. https://doi.org/10.1186/1472-6963-10-217

15. Hughes AJ, Daniel SE, Kilford L, Lees AJ. Accuracy of clinical diagnosis of idiopathic Parkinson's disease: a clinico-pathological study of 100 cases. J Neurol Neurosurg Psychiatry. 1992 Mar;55(3):181-4. https://doi.org/10.1136/jnnp.55.3.181

16. Hoehn MM, Yahr MD. Parkinsonism: onset, progression and mortality. Neurology. 1967 May;17(5):427-42. https://doi.org/10.1212/WNL.17.5.427

17. Goetz CG, Poewe W, Rascol O, Sampaio C, Stebbins GT, Counsell C et al. Movement Disorder Society Task Force report on the Hoehn and Yahr staging scale: status and recommendations. Mov Disord. 2004 Sep;19(9):1020-8. https://doi.org/10.1002/mds.20213

18. National Institute for Health and Care Excellence - NICE. Parkinson's disease: diagnosis and management in primary and secondary care. London: National Institute for Health and Care Excellence; 2006. (NICE Clinical Guideline 35)

19. Hoops S, Nazem S, Siderowf AD, Duda JE, Xie SX, Stern MB et al. Validity of the MoCA and MMSE in the detection of $\mathrm{MCl}$ and dementia in Parkinson disease. Neurology. 2009 Nov;73(21):1738-45. https://doi.org/10.1212/WNL.0b013e3181c34b47

20. Sobreira E, Pena-Pereira MA, Eckeli AL, Sobreira-Neto MA, Chagas $\mathrm{MH}$, Foss MP et al. Screening of cognitive impairment in patients with Parkinson's disease: diagnostic validity of the Brazilian versions of the Montreal Cognitive Assessment and the Addenbrooke's Cognitive Examination-Revised. Arq Neuropsiquiatr. 2015 Nov;73(11):929-33. https://doi.org/10.1590/0004-282X20150156

21. Almeida OP, Almeida SA. [Reliability of the Brazilian version of the $++a b b r e v i a t e d$ form of Geriatric Depression Scale (GDS) short form]. Arq Neuropsiquiatr. 1999 Jun;57 2B:421-6. Portuguese. https://doi.org/10.1590/S0004-282X1999000300013

22. Tumas V, Rodrigues GG, Farias TL, Crippa JA. The accuracy of diagnosis of major depression in patients with Parkinson's disease: a comparative study among the UPDRS, the geriatric depression scale and the Beck depression inventory. Arq Neuropsiquiatr. 2008 Jun;66( 2A):152-6. https://doi.org/10.1590/S0004-282X2008000200002

23. Yardley L, Beyer N, Hauer K, Kempen G, Piot-Ziegler C, Todd C. Development and initial validation of the Falls Efficacy Scale-International (FES-I). Age Ageing. 2005 Nov;34(6):614-9. https://doi.org/10.1093/ageing/afi196

24. Jonasson SB, Nilsson MH, Lexell J. Psychometric properties of the original and short versions of the Falls Efficacy Scale-International (FES-I) in people with Parkinson's disease. Health Qual Life Outcomes. 2017 May;15(1):116. https://doi.org/10.1186/s12955-017-0689-6 
25. Baggio JA, Curtarelli MB, Rodrigues GR, Tumas V. Validity of the Brazilian version of the freezing of gait questionnaire. Arq Neuropsiquiatr. 2012 Aug;70(8):599-603. https://doi.org/10.1590/S0004-282X2012000800008

26. Gibson MJ. The prevention of falls in later life: a report of the Kellogg International Work Group on the Prevention of Falls by the Elderly. Dan Med Bull. 1987 Apr;34(Suppl 4):1-24.

27. Souza AC, Magalhães LC, Teixeira-Salmela LF. [Cross-cultural adaptation and analysis of the psychometric properties in the Brazilian version of the Human Activity Profile]. Cad Saude Publica. 2006 Dec;22(12):2623-36. Portuguese. https://doi.org/10.1590/S0102-311X2006001200012

28. Lim LI, Wegen EE, Goede CJ, Jones D, Rochester L, Hetherington $\checkmark$ et al. Measuring gait and gait-related activities in Parkinson's patients own home environment: a reliability, responsiveness and feasibility study. Parkinsonism Relat Disord. 2005 Jan;11(1):19-24. https://doi.org/10.1016/j.parkreldis.2004.06.003

29. Falvo MJ, Earhart GM. Six-minute walk distance in persons with Parkinson disease: a hierarchical regression model. Arch Phys Med Rehabil. 2009 Jun;90(6):1004-8. https://doi.org/10.1016/j.apmr.2008.12.018

30. Maia AC, Rodrigues-de-Paula F, Magalhães LC, Teixeira RL. Crosscultural adaptation and analysis of the psychometric properties of the Balance Evaluation Systems Test and MiniBESTest in the elderly and individuals with Parkinson's disease: application of the Rasch model. Braz J Phys Ther. 2013 May-Jun;17(3):195-217. https://doi.org/10.1590/S1413-35552012005000085

31. Keus SH, Bloem BR, Verbaan D, Jonge PA, Hofman M, Hilten BJ et al. Physiotherapy in Parkinson's disease: utilisation and patient satisfaction. J Neurol. 2004 Jun;251(6):680-7. https://doi.org/10.1007/s00415-004-0402-7
32. Mutch WJ, Strudwick A, Roy SK, Downie AW. Parkinson's disease: disability, review, and management. $\mathrm{Br}$ Med J (Clin Res Ed). 1986 Sep;293(6548):675-7. https://doi.org/10.1136/bmj.293.6548.675 PMID:3092977

33. Agu KA, Obi El, Eze BI, Okenwa WO. Attitude towards informed consent practice in a developing country: a community-based assessment of the role of educational status. BMC Med Ethics. 2014 Oct;15:77. https://doi.org/10.1186/1472-6939-15-77

34. Costa CMFN, Silveira MR, Acurcio FA, Guerra Junior AA, Guibu IA, Costa EA et al. Use of medicines by patients of the primary health care of the Brazilian Unified Health System. Rev Saúde Pública. 2017;51(Supl 2):18s. https://doi.org/10.11606/s1518-8787.2017051007144

35. Aldosari MA, Tavares MA, Matta-Machado AT, Abreu MH. Factors associated with patients' satisfaction in Brazilian dental primary health care. PLoS One. 2017 Nov;12(11):e0187993. https://doi.org/10.1371/journal.pone.0187993

36. Dormandy E, Tsui EY, Marteau TM. Development of a measure of informed choice suitable for use in low literacy populations. Patient Educ Couns. 2007 Jun;66(3):278-95. https://doi.org/10.1016/j.pec.2007.01.001

37. Zite NB, Wallace LS. Use of a low-literacy informed consent form to improve women's understanding of tubal sterilization: a randomized controlled trial. Obstet Gynecol. 2011 May;117(5):11606. https://doi.org/10.1097/AOG.0b013e318213cbb1

38. ATS Committee on Proficiency Standards for Clinical Pulmonary Function Laboratories. ATS statement: guidelines for the sixminute walk test. Am J Respir Crit Care Med. 2002 Jul;166(1):111-7. https://doi.org/10.1164/ajrccm.166.1.at1102

39. Flach A, Jaegers L, Krieger M, Bixler E, Kelly P, Weiss EP et al. Endurance exercise improves function in individuals with Parkinson's disease: A meta-analysis. Neurosci Lett. 2017 Oct;659:115-9. https://doi.org/10.1016/j.neulet.2017.08.076 